\title{
The Advanced Technology Corvette - Railgun (ATK-R) Design Study - Future Weapons and Small Ship Power Systems
}

\author{
R J Pawling* MEng PhD CEng AMRINA, L Farrier* MEng MSc AMIMarEST, R Bucknall* MIET, \\ MSNAME, MIMarEST
}

* UCL, Department of Mechanical Engineering, London, UK

* Corresponding Author. Email: r.pawling@ucl.ac.uk

\section{Synopsis}

\begin{abstract}
High-power electric weapons, such as the ElectroMagnetic RailGun (EMRG), laser and High Power Microwave devices are moving closer to practical utilisation by navies, and prototype EMRG systems are being tested at militarily useful energy levels. Previous work in the UCL Department of Mechanical Engineering includes; preliminary design studies for surface combatants with an all-electric weapons outfit; and detailed marine engineering analysis, to $\mathrm{PhD}$ level, of the implications for future power and propulsion systems of these weapons. Design studies for electrically armed ships have generally examined large destroyer-sized surface combatants, with significant installed electrical power. This paper describes a concept design study for a small corvette-sized combatant, ATK-R, developed as the "minimum sized ship" capable of supporting an EMRG as its primary armament This paper describes the UCL ZEOLIT design tool, the ship design impacts and marine engineering integration of this future concept including the use of Energy Storage Systems (ESS) and the choice between power limited (Patrol vessel -like) and power dense (Fast attack craft -like) power and propulsion systems.
\end{abstract}

Keywords: Railgun; Small warships; Energy storage; Concept design

\section{Introduction}

Naval ship propulsion has moved towards electrification, with larger ships favouring hybrid and Integrated Full Electric Propulsion (IFEP) (Simmonds, 2016). High-power electric weapons, such as the electromagnetic railgun (EMRG), laser and High Power Microwave (HPM) devices are moving closer to practical utilisation. The Marine Engineering Group (MRG), part of the Department of Mechanical Engineering at UCL, has investigated the impacts of electric weapons on various aspects of ship design. This has included design studies such as those presented by Andrews et al (2010) and (2011), and detailed investigations of the marine engineering aspects, up to $\mathrm{PhD}$ level research. The earliest UCL design for an all-electric ship, presented in 2010, is illustrated in Figure 1, with principal particulars in Table 1. A hypothetical successor to the RN Type 45 destroyer, this large vessel featured sufficient installed electrical generation to support multiple high-power weapons.

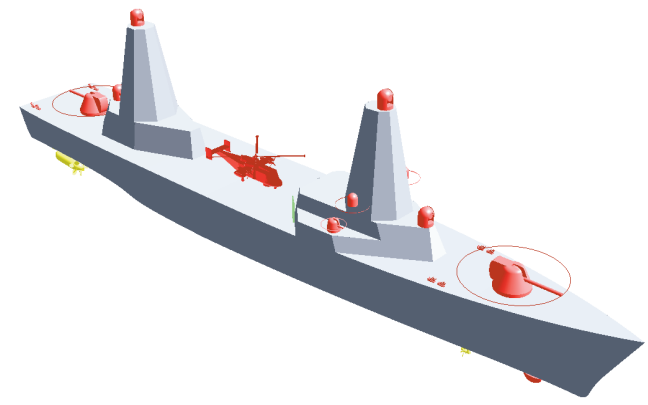

Figure 1: UCL electrically armed destroyer of 2010 (Andrews et al, 2010)

Table 1: Principal particulars of the 2010 UCL all-electric destroyer design

\footnotetext{
Author's Biographies

Dr. Rachel Pawling is a Lecturer in Ship Design at UCL, teaching the subject of ship design to undergraduate and postgraduate students. She obtained her PhD in computer aided ship design in 2007 and has subsequently continued her research in projects funded by the EC, UK and US governments.

Mr. Luke Farrier is a Marine Engineering Research Assistant at UCL and 2nd year PhD student investigating power system performance when integrating energy storage systems. Prior to this he obtained a degree in Mechanical Engineering from the University of Exeter, and an MSc in Marine Engineering (Electrical) from UCL.

Prof. Richard Bucknall is the Professor of Marine and Power Systems Engineering and the Department's Director of Research. His areas of interest include low carbon shipping, hybrid and fuel cell propulsion, autonomous vehicles. His collaborative projects have included industry partners such as UK MoD, Rolls Royce and BMT and he works internationally with organisations in EU, China and USA.
} 


\begin{tabular}{l|l|l|l} 
Displacement & 8740 tonnes (deep) & Installed Power & $63.2 \mathrm{MW}$ \\
Internal Volume & $36500 \mathrm{~m}^{3}$ & Propulsion Type & IFEP + pods \\
Length (oa) & $151 \mathrm{~m}$ & Electric Weapons & $2 \times 62.5 \mathrm{MJ}$ railgun \\
Beam (oa) & $21.7 \mathrm{~m}$ & & $2 \times 1.5 \mathrm{MW}$ IR laser \\
Draught & $5.6 \mathrm{~m}$ & $2 \times 0.6 \mathrm{MJ}$ railgun \\
Max. Speed & $29 \mathrm{knots}$ & &
\end{tabular}

Whitelegg (2016a, 2016b) investigated the transient and harmonic impacts of an EMRG with 64 MJ muzzle energy on a candidate warship AC power system under pre-defined shot patterns using time-domain simulation methods. The modelled system comprised a $36 \mathrm{MW}$ gas turbine alternator (GTA) providing power to the EMRG via controlled thyristor rectifier and capacitor bank ESS. The research findings showed that to maintain QPS within NATO STANAG 1008 limits at a firing rate of 12 shots per minute, the ESS needed to store 305 MJ, to provide residual charge sufficient to reduce the inrush current following an EMRG shot.

\section{The UCL ship design toolset "ZEOLIT"}

The UCL MRG has an established history in the development of concept design approaches for complex ships, notably the Design Building Block Approach (DBBA), an architecturally-centred approach to early stage design first outlined by Andrews (1998), subsequently implemented within the Paramarine software and recently in a Javascript web application (Pawling et al, 2015). These tools have been applied to design investigations involving a small number of "point" design studies. There are, however, other approaches to early stage ship design combining architectural aspects and wide ranging numerical exploration, including the TUDelft Packing Approach (Van Oers, 2011) and University of Michigan developed Intelligent Ship Arrangements (ISA) (Daniels et al, 2009).

The approach developed for the ATK-R study follows previous UCL work on a library-based approach to concept ship design, in which a wide range of possible design solutions were generated by combining precalculated "partial" solutions from a library (McDonald et al, 2012). Examples included a range of hullform types varying in displacement and proportions; or different machinery topologies. The current state of the concept design would thus be represented by a "cloud" of possible design points, which could be refined over time. This approach has similarities to the "Set Based Design" method (Singer et al, 2009) in that, rather than developing a detailed representation of the current design solution, the concept exploration proceeds by developing parametric models of different features of the design, then uses numerical exploration approaches to combine the different models. The new UCL approach has been implemented as an Excel-based tool known as "ZEOLIT" (Zonal Exploration Of Layout and Impacts Tool).

\subsection{Representing layouts in ZEOLIT}

ZEOLIT includes arrangement in a simple and fast design exploration, by describing the ship's layout as a grid of 32 layout zones; 8 divisions along the length of the ship and four vertically (upper superstructure, No 1 deck, No 2 deck and lower hull). Spaces and equipment (equivalent to Design Building Blocks, DBB) are assigned to these layout zones, and the current topology of the ships' internal envelope is separated from the library of precalculated hulls as shown in Table 2.

Table 2: Layout modelling in ZEOLIT

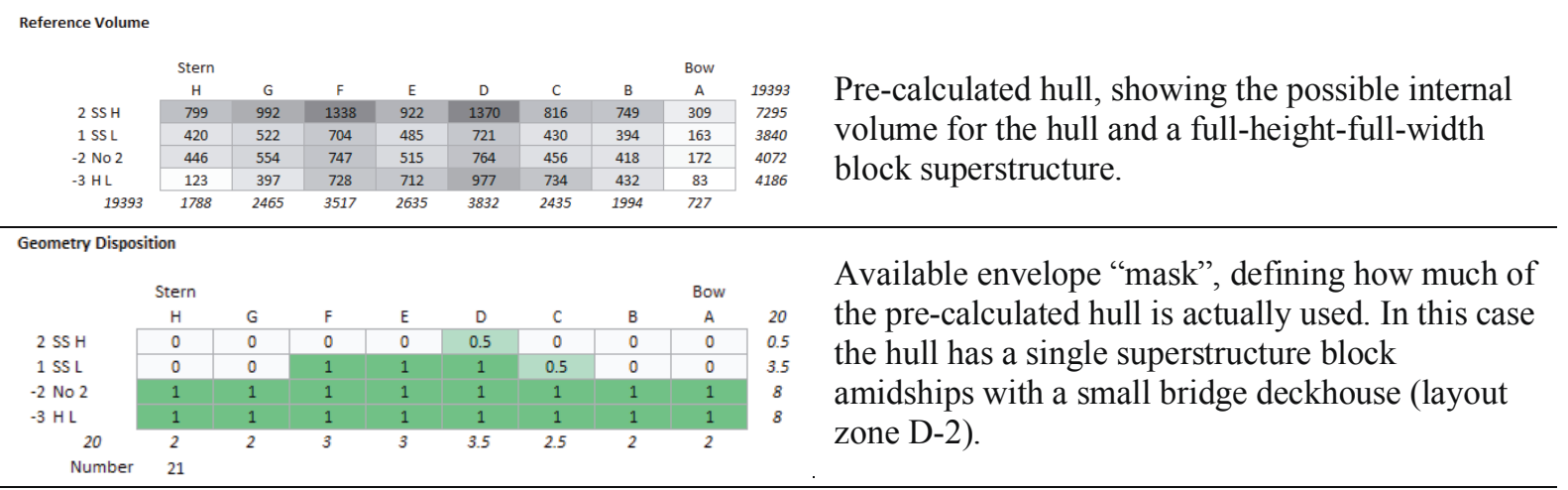




\begin{tabular}{|c|c|c|c|c|c|c|c|c|c|c|}
\hline \multicolumn{11}{|c|}{ Item Distribution Inspector } \\
\hline & 4 & & & & & & & & \multirow{9}{*}{$\begin{array}{l}1 \\
0 \\
0 \\
0 \\
1\end{array}$} & \multirow{9}{*}{$\begin{array}{l}\text { Spaces and equipment are assigned to layout- } \\
\text { zones. Distributed items, such as fuel tanks, can be } \\
\text { assigned to multiple zones as fractions. } \\
\text { Alternatively, a pseudo-random assignment can be } \\
\text { used where the designer specifies the probability } \\
\text { of being in a certain layout zone. }\end{array}$} \\
\hline & $\begin{array}{c}\text { Stern } \\
\mathrm{H}\end{array}$ & G & $\mathrm{F}$ & E & D & c & B & $\begin{array}{c}\text { Bow } \\
\text { A }\end{array}$ & & \\
\hline $2 \mathrm{SSH}$ & 0 & 0 & 0 & 0 & 0 & 0 & 0 & 0 & & \\
\hline $1 \mathrm{SSL}$ & 0 & 0 & 0 & 0 & 0 & 0 & 0 & 0 & & \\
\hline-2 No 2 & 0 & 0 & 0 & 0 & 0 & 0 & 0 & 0 & & \\
\hline$-3 \mathrm{HL}$ & 0 & 0.25 & 0.1 & 0 & 0.25 & 0.4 & 0 & 0 & & \\
\hline 1 & 0 & 0.25 & 0.1 & 0 & 0.25 & 0.4 & 0 & 0 & & \\
\hline \multicolumn{9}{|c|}{ Inspecting Liquid Fuel Tanks } & & \\
\hline Numbe & 4 & & & & & & & & & \\
\hline \multicolumn{11}{|l|}{ Current Volume } \\
\hline \multicolumn{9}{|l|}{ FG: move } & \multirow{7}{*}{$\begin{array}{c}2406 \\
187 \\
0 \\
131 \\
2088\end{array}$} & \multirow{7}{*}{$\begin{array}{l}\text { The current volume required in each layout-zone } \\
\text { can be calculated, shown here for the entire } \\
\text { "move" function (i.e. machinery, fuel tanks etc.) }\end{array}$} \\
\hline & Stern & & & & & & \multirow{2}{*}{\multicolumn{2}{|c|}{$\begin{array}{c}\text { Bow } \\
\text { A }\end{array}$}} & & \\
\hline & $\mathrm{H}$ & G & $\mathrm{F}$ & E & $\mathrm{D}$ & c & & & & \\
\hline $2 \mathrm{SSH}$ & 0 & 0 & 0 & 0 & 187 & 0 & 0 & 0 & & \\
\hline $1 \mathrm{SSL}$ & 0 & 0 & 0 & 0 & 0 & 0 & 0 & 0 & & \\
\hline-2 No 2 & 0 & 0 & 104 & 27 & 0 & 0 & 0 & 0 & & \\
\hline $\begin{array}{l}-3 \mathrm{HL} \\
2406\end{array}$ & $\begin{array}{l}255 \\
255\end{array}$ & $\begin{array}{l}187 \\
187\end{array}$ & $\begin{array}{r}355 \\
459\end{array}$ & 759 & $\begin{array}{l}258 \\
445\end{array}$ & $\begin{array}{l}274 \\
274\end{array}$ & 0 & 0 & & \\
\hline \multirow{2}{*}{\multicolumn{2}{|c|}{ Current Total Volume }} & \multirow{2}{*}{\multicolumn{2}{|c|}{ Update totals }} & & & & & & \multirow{8}{*}{$\begin{array}{c}9280 \\
\\
332 \\
1676 \\
3758 \\
3514\end{array}$} & \multirow{8}{*}{$\begin{array}{l}\text { This aggregation can be repeated over all functions } \\
\text { and all layout zones to calculate the total volume } \\
\text { (and weight) in each zone. }\end{array}$} \\
\hline & & & & & & & & & & \\
\hline \multicolumn{2}{|r|}{$\begin{array}{c}\text { Stern } \\
\mathrm{H}\end{array}$} & G & $\mathrm{F}$ & E & D & c & B & Bow & & \\
\hline $2 \mathrm{SSH}$ & 0 & 0 & 0 & 0 & 332 & 0 & 0 & 0 & & \\
\hline $1 \mathrm{SSL}$ & 0 & 9 & 575 & 447 & 474 & 163 & 9 & 0 & & \\
\hline-2 No 2 & 448 & 496 & 621 & 428 & 647 & 401 & 273 & 443 & & \\
\hline$-3 \mathrm{HL}$ & 275 & 435 & 504 & 954 & 381 & 466 & 303 & 196 & & \\
\hline 9280 & 723 & 940 & 1699 & 1830 & 1834 & 1030 & 584 & 639 & & \\
\hline
\end{tabular}

\subsection{The hullform library and calculation approach}

ZEOLIT currently contains a reference library of 5832 monohull forms, between 500 and 4000 tonnes, with variations in various hullform parameters. In addition to dimensions and the available volumes, the library includes basic hydrostatic information and a simplified power-speed curve between 3.5 and 35 knots. ZEOLIT applies the specified layout and sizing equations for Design Building Blocks to each hull option in turn. Those that fall with user-defined limits for overall weight and space balance (defined as the ratio of volume available to volume required and hull displacement to total mass) are retained and all others discarded. A typical plot of values for the overall volume and mass ratios is shown in Figure 2, illustrates that ZEOLIT can provide a wide range of options even with a small window of acceptability $(+/-5 \%$ in this case).

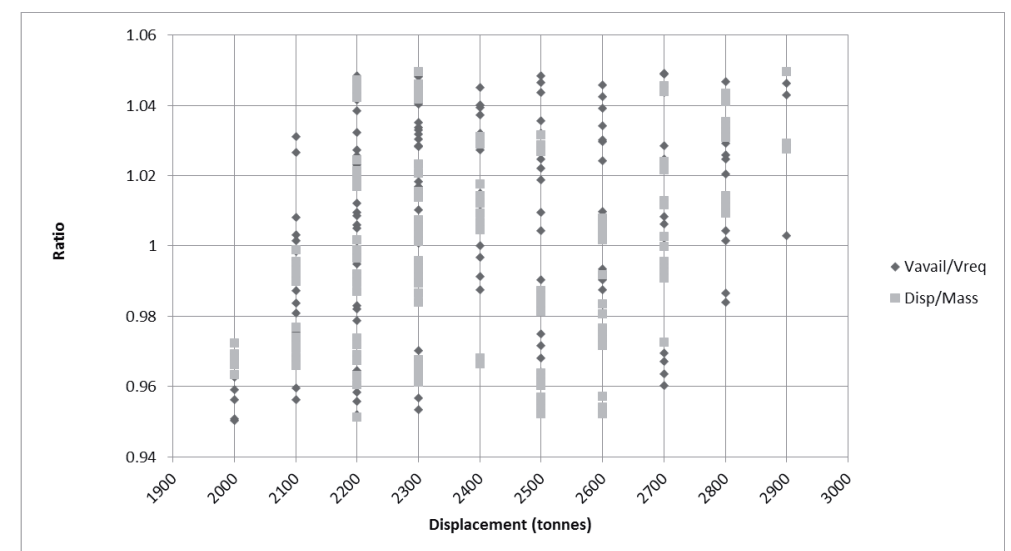

Figure 2: ZEOLIT output, showing the variation in volume and mass ratios within the acceptable range.

Each design option can be inspected individually, but the main use for ZEOLIT is in comparing a "cloud" of designs to understand general trends and statistics in the acceptable range. Similarly, volume and weight values for each DBB are defined by three point estimates (low, typical, high) and calculations can be run with each of these conditions, or a random mix. The aim with a statistical approach being to understand the sensitivity of the design to inputs and uncertainty. ZEOLIT makes use of both parametric models for sub-systems (e.g. for a batterybased ESS) and lookup tables of precalculated options. The former is most applicable where system sizing has several inputs and is complex. The latter is most applicable where system sizing has few inputs, or where models are too slow to be used at run-time. 


\subsection{Assessing layouts in ZEOLIT}

For each layout zone and option, ZEOLIT records the ratio of available to required volume. This is grouped into four user-defined levels; much too small ( $<80 \%$ ), slightly too small (80-95\%), satisfactory (95-110\%), slightly too big (110-120\%) and far too big (>120\%). The percentage of possible design options in these ranges is illustrated as shown in Figure 3 allowing the designer to evaluate the arrangement over a range of options, rather than a single point design.

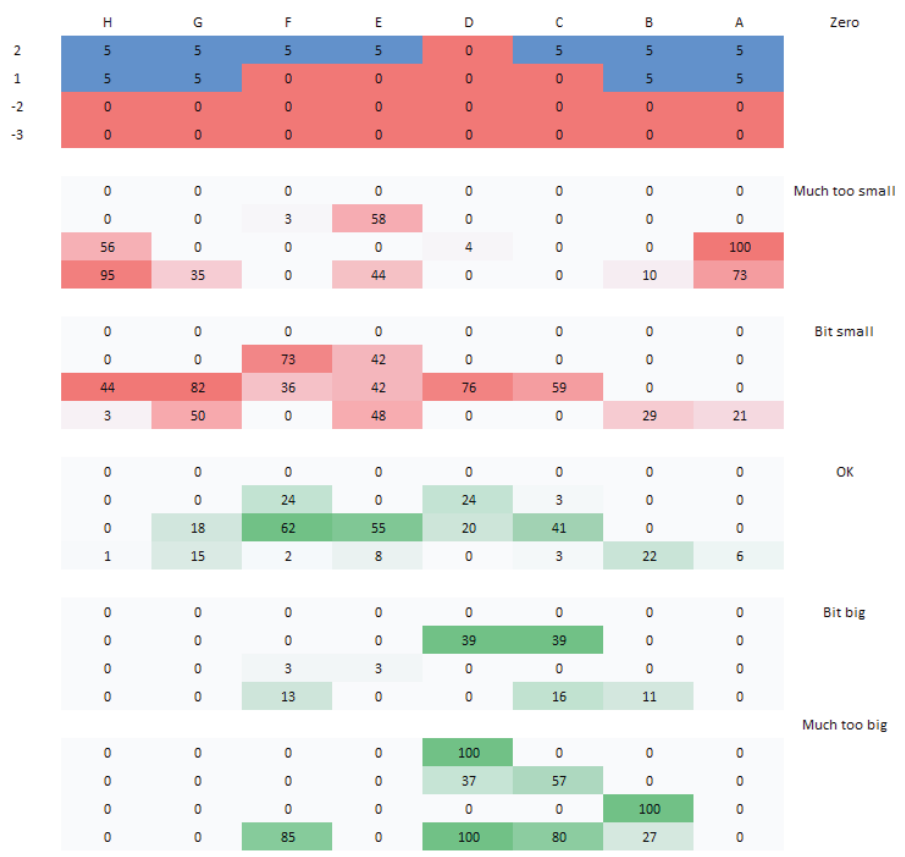

Figure 3: Visualisation of the percentage of options meeting volume availability criteria

\section{The Advanced Technology Corvette - Railgun}

The work reported in this paper is part of an ongoing study known as the "Advanced Technology Corvette Railgun", or ATK-R. This examines the smallest ships that can carry electric weapons, where "small ship" in this case is defined as 500-4000 tonnes standard displacement. ATK-R acts as a focus/interchange point for several separate areas of research and development at UCL, summarised in Figure 4 This paper covers the naval architecture and marine engineering aspects of the project, with combat systems to be described in a later paper.

Advanced Technology Korvette - Railgun

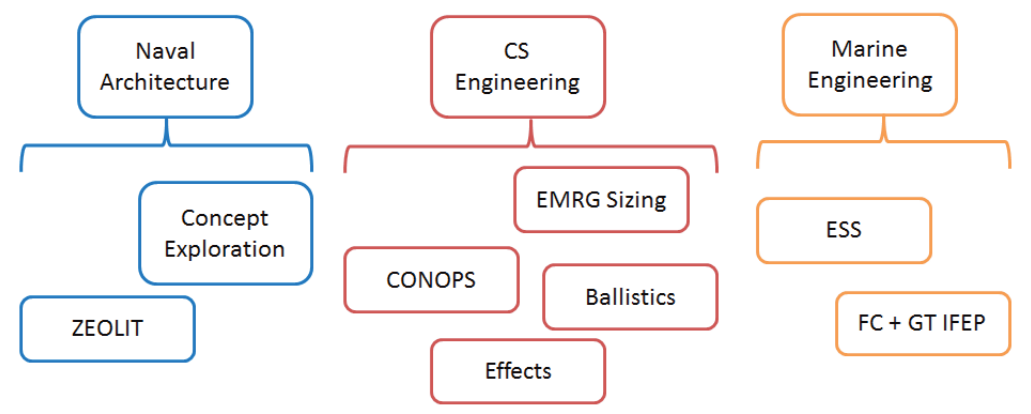

Figure 4: Areas of research brought together in ATK-R 


\subsection{Requirements}

\subsubsection{Common specifications}

A common set of specifications and combat system elements were used across all design variants developed at the time of writing. None of these is hard-coded and all can be changed by the designer (including using VBA scripting to assess multiple options). These are summarised in Table 3. The baseline design used a conventional configuration with the railgun forward, machinery amidships and accommodation distributed on No 2 deck as illustrated by Figure 5.

Table 3: Common specifications for ATK-R

\begin{tabular}{l|l|l|l} 
Complement & 50 & Deck height & $2.75 \mathrm{~m}$ \\
Stores endurance & 30 days & DC zones & 3 \\
Fuel endurance & 14 days & Boats and craft & $1 \times 7 \mathrm{~m}$ RIB \\
& & & $330 \mathrm{~m}^{3} \mathrm{UxV}$ bay
\end{tabular}

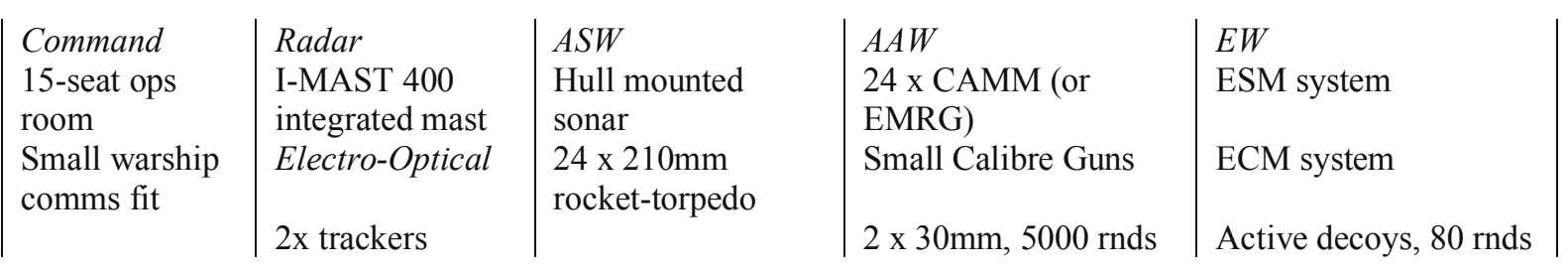

\begin{tabular}{|c|c|c|c|c|c|c|c|}
\hline Stern & & & & & & & Bow \\
\hline $\mathrm{H}$ & G & $\mathrm{F}$ & $E$ & D & C & B & A \\
\hline 0 & 0 & 0 & 0 & 0 & 0 & 0 & 0 \\
\hline 0 & 0 & 400 & 330 & 0 & 15 & 0 & 0 \\
\hline 324 & 46 & 142 & 41 & 29 & 31 & 96 & 329 \\
\hline 19 & 98 & 68 & 19 & 39 & 54 & 58 & 126 \\
\hline
\end{tabular}

FLOAT functional group

\begin{tabular}{|c|c|c|c|c|c|c|c|}
\multicolumn{1}{c}{$\begin{array}{c}\text { Stern } \\
\text { H }\end{array}$} & G & F & E & D & C & B & A \\
\hline 0 & 0 & 0 & 0 & 47 & 0 & 0 & 0 \\
\hline 0 & 8 & 46 & 0 & 226 & 34 & 8 & 0 \\
\hline 9 & 25 & 0 & 25 & 134 & 0 & 170 & 0 \\
\hline 0 & 0 & 0 & 44 & 0 & 0 & 82 & 25 \\
\hline
\end{tabular}

FIGHT functional group

\begin{tabular}{|c|c|c|c|c|c|c|c|}
\hline \multicolumn{7}{|l|}{ Stern } & \multirow{2}{*}{$\begin{array}{c}\text { Bow } \\
\text { A }\end{array}$} \\
\hline $\mathrm{H}$ & G & $\mathrm{F}$ & $\mathrm{E}$ & D & C & B & \\
\hline 0 & 0 & 0 & 0 & 178 & 0 & 0 & 0 \\
\hline 0 & 0 & 0 & 0 & 0 & 0 & 0 & 0 \\
\hline 0 & 0 & 99 & 25 & 0 & 0 & 0 & 0 \\
\hline 194 & 195 & 396 & 670 & 213 & 269 & 0 & 0 \\
\hline \multicolumn{8}{|c|}{ MOVE functional group } \\
\hline Stern & & & & & & & Bow \\
\hline $\mathrm{H}$ & G & $\mathrm{F}$ & $\mathrm{E}$ & D & C & B & A \\
\hline 0 & 0 & 0 & 0 & 1 & 0 & 0 & 0 \\
\hline 0 & 0 & 11 & 8 & 105 & 16 & 0 & 0 \\
\hline 5 & 282 & 234 & 201 & 326 & 235 & 45 & 5 \\
\hline 0 & 64 & 3 & 32 & 8 & 23 & 0 & 0 \\
\hline
\end{tabular}

INFRASTRUCTURE functional group

Figure 5: Distribution of volume demands for an example option, for the four Functional Groups in the ATK$\mathrm{R}$ baseline study, with darker grey indicating a greater demand.

\subsubsection{Speed}

Fuel requirements were calculated by applying one of two operational profiles, shown in Figure 6, over a period of 14 days. Propulsion machinery was sized for three speeds: slow cruise (14 knots); fast cruise (21 knots) and maximum speed ( 25 or 35 knots) with a sea margin of $10 \%$. The ships' electrical load has a margin of $25 \%$ and generators are sized for a maximum activity load of $75 \%$ of the total connected load (TCL), with endurance calculated at $50 \%$ TCL. Chilled water plants for the ship include a $25 \%$ margin. These can be subjected to sensitivity surveys using VBA automation. 

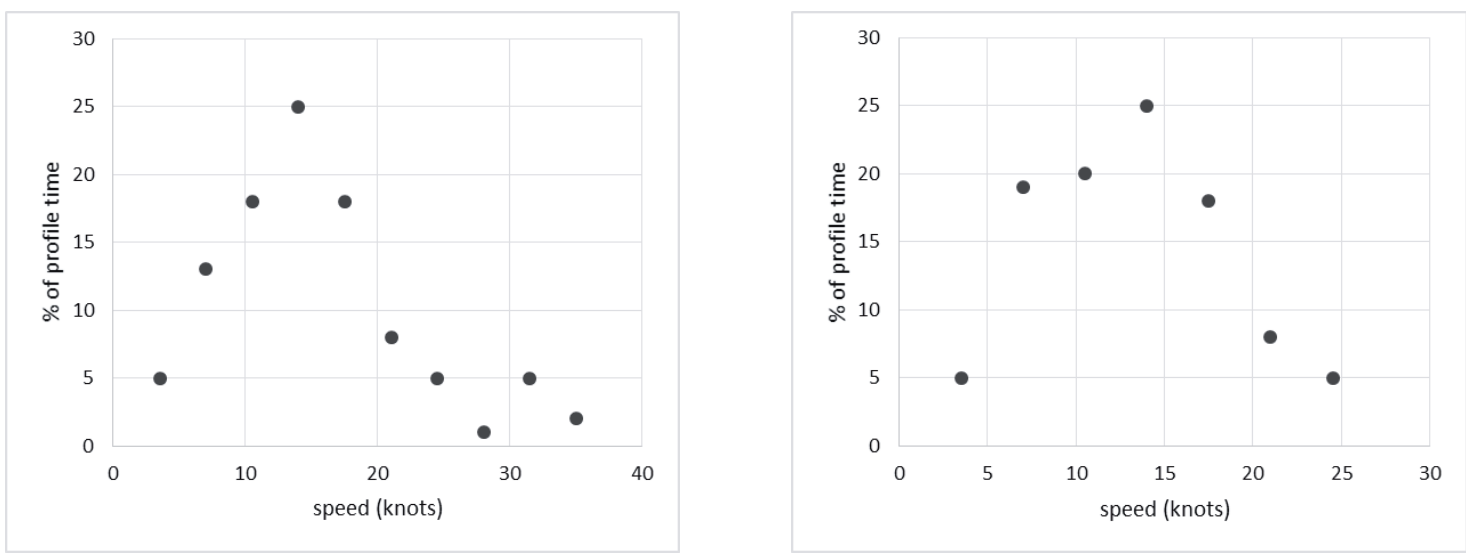

Figure 6: Operational profiles for the two maximum speed options (left $=35$ knots, right $=25$ knots)

\subsection{Railgun options}

Figure 7 (Andrews et al, 2010) illustrates a generic ElectroMagnetic RailGun (EMRG). The conducting armature is accelerated down the barrel by Lorentz forces, with typical in-bore times of 10ns. The GW-level short duration pulses required are generated by a Pulse Forming Network (PFN), typically fed by a weapon-dedicated ESS. ESS to PFN discharge times are determined by the rate of fire of the weapon, whilst the time taken to charge the ESS is a factor of the number of shots stored in the ESS and the engagement timeline. Figure 7 shows energy flow back into the ESS - as EMRG are typically $40-50 \%$ efficient at best, it is possible to recover some electrical energy from the rails via a muzzle shunt.

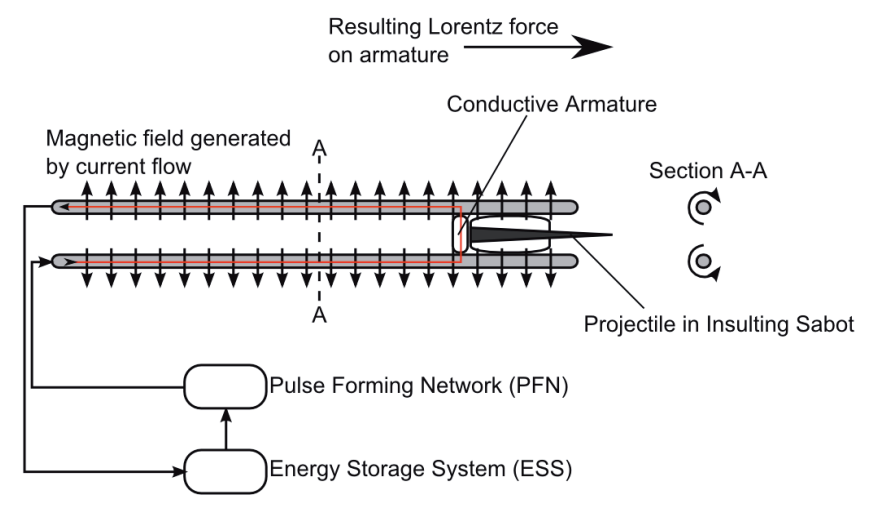

Figure 7: Block diagram of a generic electromagnetic railgun (Andrews et al, 2010)

ATK-R includes a range of weapon sizes, summarised in Table 4. These range from a large calibre gun similar to the 64MJ weapons identified by the US Navy as a goal $(\mathrm{ONR}, 2008)$ to smaller calibre anti-air weapons, closer to the Blitzer prototype (General Atomics, 2018). Also of interest is the use of the large-calibre EMRG in a low power mode to launch a small UAV for reconnaissance. The physical size of the weapons has been estimated using the models previously used in UCL studies. Associated with the EMRG options are engagement scenarios, summarised in Table 5. These are either continuous, in which the EMRG fires several rounds and then does not fire again in the scenario; or burst, in which the EMRG must fire several bursts of rounds in the same scenario. 


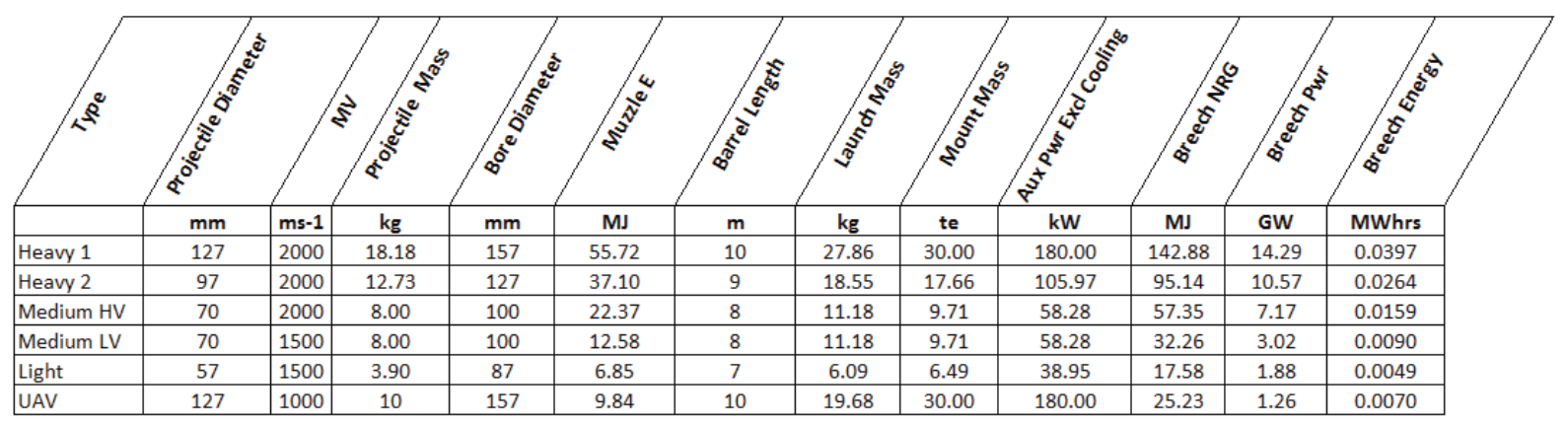

Table 4: The range of EMRG sizes under investigation

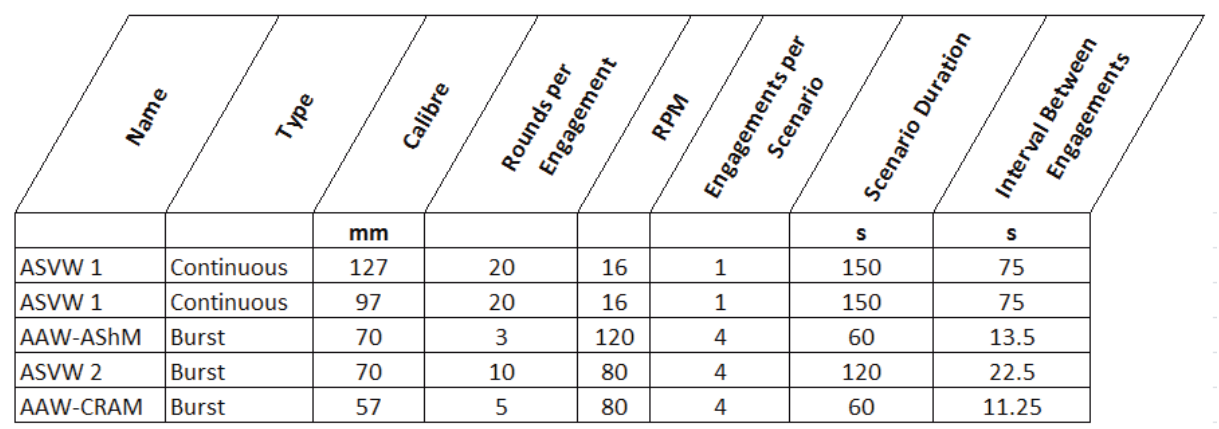

Table 5: Engagement scenarios initially under investigation

\section{Power and propulsion system topologies and technologies for ATK-R}

\subsection{Future power and propulsion system technologies}

Present power generation on electric warships is most commonly by mechanical prime movers driving synchronous generators providing fixed frequency AC voltage. Increasing on-board power demand is driving improved power density and energy efficiency of machines and prime movers. The former requirement is being targeted through advanced technologies that include water-cooled wound field, permanent magnet and high temperature superconducting (HTS) generators. Alternatively, matching the speed of the generator more closely to the prime mover resulting in higher frequency power generation $(200-400 \mathrm{~Hz})$, this can result in a higher power density to $60 \mathrm{~Hz}$ counterparts (Calfo et al., 2008).

Fuel cells are a power source considered for future warships (Doerry et al. 2015). Proton Exchange Membrane Fuel Cells (PEMFCs) have successfully been used in submarine applications, but require high purity hydrogen (necessitating reformation from hydrocarbon fuels) and their low temperature operation discounts the opportunity of heat recovery, subsequently overall efficiency ranges from 50-60\%. Solid Oxide Fuel Cells (SOFCs) operate at high temperatures $\left(500-1000^{\circ} \mathrm{C}\right)$ and can use hydrocarbons via internal steam reformation to generate hydrogen. Total fuel efficiency of SOFCs can reach $85 \%$ when integrated with heat recovery systems (DNV-GL, 2017). However, high temperature operation incurs long start up times and low ramp rates, requiring an alternative fast-acting power source.

Present warship power distribution topologies are primarily based upon 3-wire AC distribution (Meggs and Pollard, 2016). DC architectures for naval vessels are attractive for integration of pulsed loads such as EMRGs, owing to the lack of requirement for synchronisation between power sources as the sources are managed by dedicated power electronic converters. The converters would increase cooling demand, however this could be overcome by using semiconductor devices with Silicon Carbide to reduce switching and conduction losses (Gattozzi et al, 2017). DC distribution allows contribution from a number of on-board power sources to supply the PFN of the EMRG as opposed to a single dedicated source and is therefore beneficial for the ATK-R. The challenge of DC is the potential of power system instability when high ramp loads induce voltage drop caused by unbalanced power flow, advanced energy management being a possible solution (Vu, Gonsoulin, Perkins, et al. 2017).

The state-of-the-art for current naval electric propulsion motors is arguably the advanced induction motor. Other options include permanent magnet and HTS motors. For ships with limited machinery space volume such as corvettes, electric propulsion using high-speed motors driving the propeller shaft via a reduction gearbox is an 
attractive alternative to larger, heavier shaft mounted motors (Chowaniec et al., 2012) or the higher cost option of the HTS that requires a cryogenic cooling system for the superconducting field winding.

\subsection{System topologies considered}

At the time of writing, three power and propulsion topologies have been examined in ZEOLIT. These topologies are summarised in Table 6. All diesels are assumed to be high speed engines. DC power distribution is included in each topology for the reasons discussed in section 4.1.

Table 6: System topologies

\begin{tabular}{|c|c|c|c|c|c|c|}
\hline Topology & $\begin{array}{l}\text { Max } \\
\text { Speed }\end{array}$ & Type & $\begin{array}{l}\text { Power } \\
\text { distro }\end{array}$ & Propulsion & Prime movers & ESS \\
\hline $1 \mathrm{a}$ & 35 & Hybrid & $\mathrm{DC}$ & $\begin{array}{l}2 \times \text { propellers driven by } \\
\text { high speed geared motors } \\
1 \mathrm{x} \text { waterjet }\end{array}$ & $\begin{array}{l}2 \times \text { small DG } \\
2 \times \text { medium DG } \\
1 \times \text { high speed } \\
\text { GTA }\end{array}$ & $\begin{array}{l}\text { Hybrid battery/ } \\
\text { supercapacitor }\end{array}$ \\
\hline $1 b$ & 35 & Hybrid & $\mathrm{DC}$ & $\begin{array}{l}2 \mathrm{x} \text { propellers driven by } \\
\text { high speed geared motors } \\
1 \text { or } 2 \mathrm{x} \text { waterjet }\end{array}$ & $\begin{array}{l}2 \times \text { small DG } \\
2 \times \text { medium DG } \\
1 \text { or } 2 \times \text { high speed } \\
\text { GTA }\end{array}$ & $\begin{array}{l}\text { Hybrid battery/ } \\
\text { supercapacitor }\end{array}$ \\
\hline $2 a$ & 25 & IFEP & $\mathrm{DC}$ & $\begin{array}{l}2 \times \text { propellers driven by } \\
\text { high speed geared motors }\end{array}$ & $\begin{array}{l}2 \times \text { small DG } \\
2 \times \text { large DG }\end{array}$ & $\begin{array}{l}\text { Hybrid battery/ } \\
\text { supercapacitor }\end{array}$ \\
\hline $2 b$ & 25 & IFEP & DC & $\begin{array}{l}2 \times \text { propellers driven by } \\
\text { high speed geared motors }\end{array}$ & $\begin{array}{l}2 \times \text { small SOFC } \\
2 \times \text { large SOFC }\end{array}$ & $\begin{array}{l}\text { Hybrid battery/ } \\
\text { supercapacitor }\end{array}$ \\
\hline
\end{tabular}

\subsubsection{Topology $1 a$}

Topology 1a is a CODLAG system, shown in Figure 8. When operating the EMRG, the waterjet is declutched and the GT is connected to a high frequency generator set via power take-off (PTO) to charge the EMRG ESS. The specifics of the gearbox design are outside the scope of this study, although weight and space is included, estimated using a parametric model fitted to available data. This topology was assessed with and without a battery ESS to support the GT when charging the EMRG ESS, the GT being sized to meet propulsion needs and thus not necessarily matched to the needs of the EMRG engagement scenario. Topology $1 \mathrm{~b}$ is as la but with multiple GT and waterjets, each with its own PTO and high speed generator.

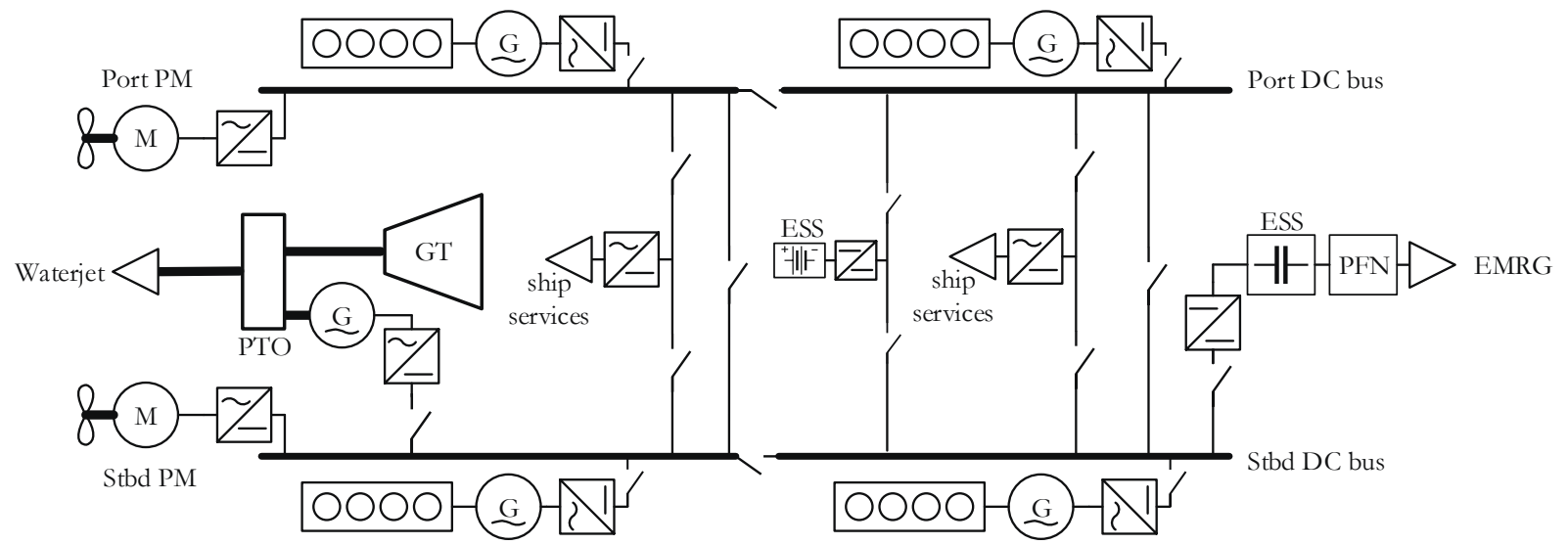

Figure 8: Line diagram of topology 1a 


\subsubsection{Topology $2 a$}

An IFEP system with no GT or waterjet, shown in Figure 9. EMRG ESS charging is facilitated by a combination of the DG sets and battery ESS. This topology was explored with maximum speed of 25 knots.

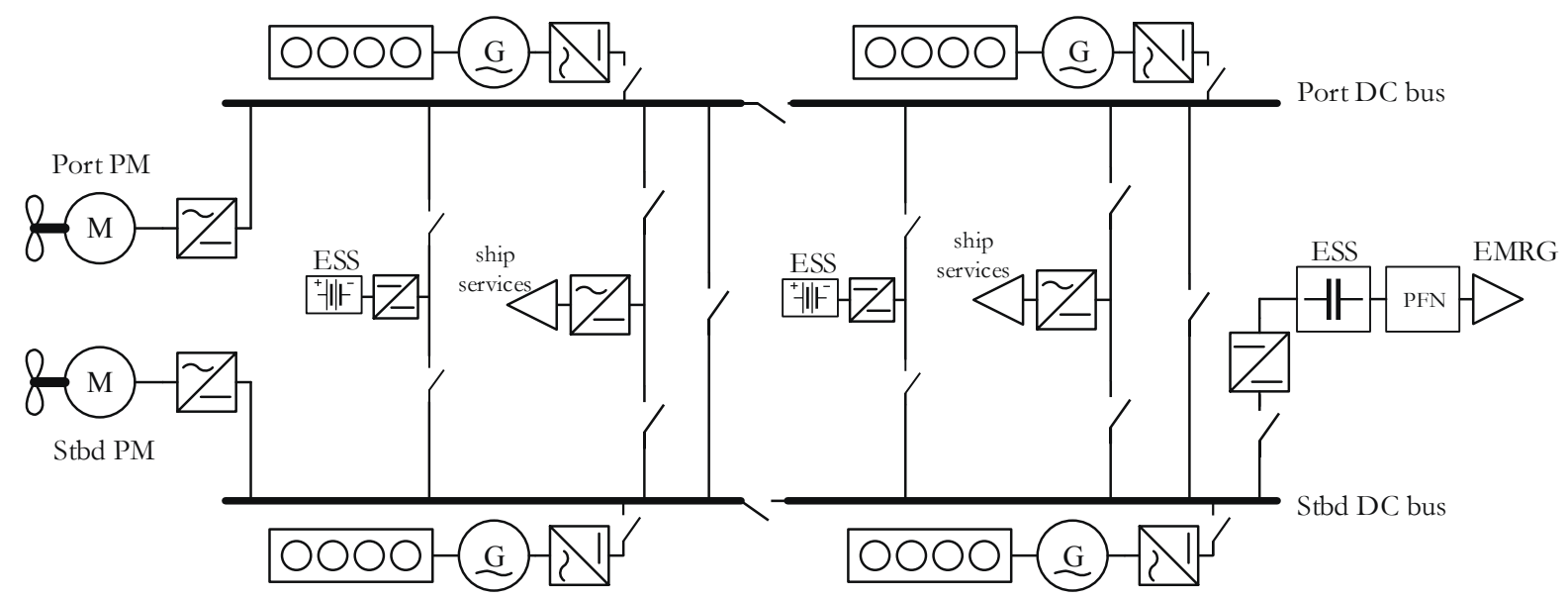

Figure 9: Line diagram of topology 2a

\subsubsection{Topology $2 b$}

Topology 2 b replaces the DGs with four SOFC stacks, running on methanol fuel and with a substantial battery ESS to support EMRG charging, as shown in Figure 10. The fuel cells were assumed to be unitised and sized for slow and high cruise speeds as with the DG. Data is scarce on SOFC and the associated waste heat recovery systems, although commercial models exist (Kyocera, 2017) and there is interest in their use on aircraft (Whyatt \& Chick, 2012). For the initial studies, the SOFC were assumed to have an efficiency of $60 \%$.

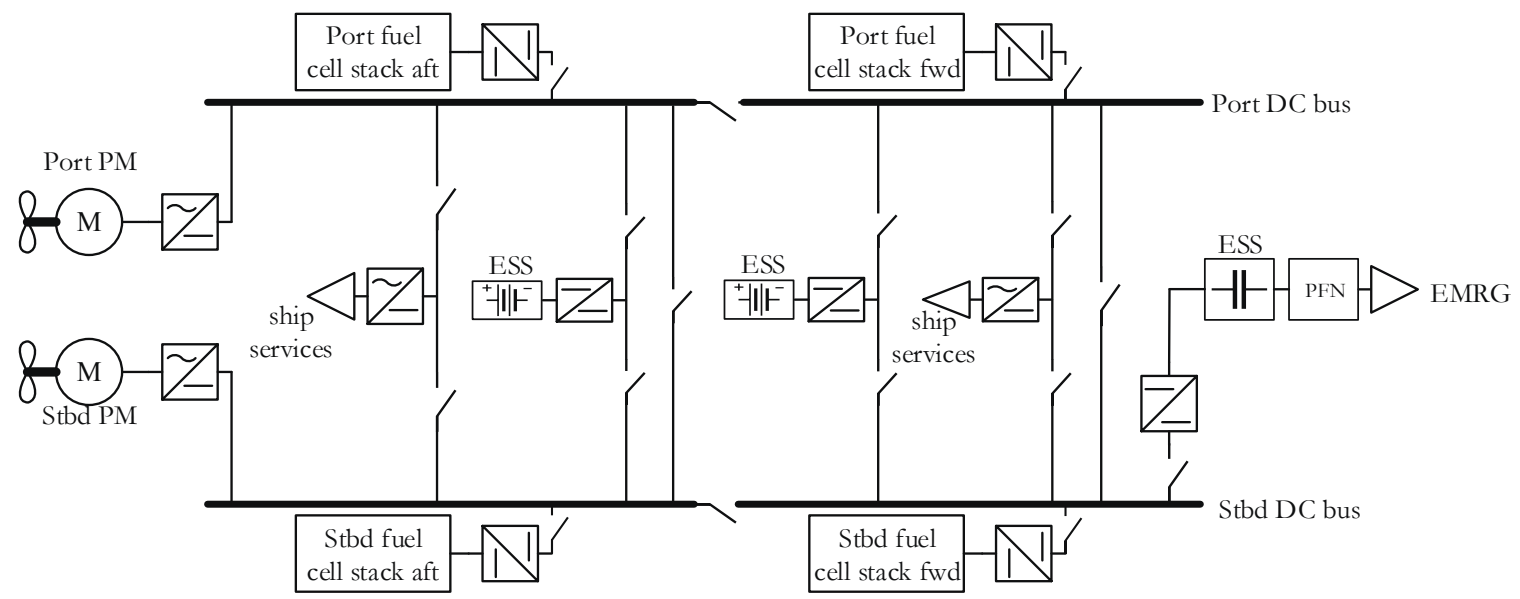

Figure 10: Line diagram of topology $2 \mathrm{~b}$

\section{The role of ESS in electric weapons on small ships}

Supplying pulsed loads from a ship's electrical power system incurs large differential load changes, requiring an ESS system to rapidly transition from supplying and absorbing energy to buffer the load seen by the generator. This mitigates the voltage and frequency transients (for AC) in the ship power system. The high discharge rates limit near-term ship ESS to flywheels and supercapacitors. Flywheels are under consideration by navies for the support of laser directed energy weapons (LDEW) and can be desirable for ships from the perspectives of fire management and cell life; flywheels can be run down and shut off when not required with no residual charge (Tate and Rumney, 2017). Supercapacitors however are very power dense, and Southall et al., (2017) noted benefits of reduced maintenance; no moving parts; and minimal noise and vibration. The selection of the energy stores is highly use case dependent and for ATK-R, a supercapacitor option was selected for the "weapon" ESS. 
EMRG weapon ESS charging requirements are demanding on a ships power system to achieve high rates of fire whilst maintaining QPS (Whitelegg, 2016). A hybrid ESS approach incorporating a battery, regarded as a "ships" ESS, provides sufficient capacity to support a proportion of the charging power to mitigate QPS impacts under EMRG operation. Batteries could also enable reductions in installed power. The ATK-R studies include the possibility of either dedicated EMRG "weapon" ESS or a battery/supercapacitor hybrid ESS to balance the power and energy requirement associated with the electric armament.

A "ship" ESS may also have secondary functions; at low speeds, the ESS could provide power to hotel load and propulsion reducing the acoustic signature and thermal signatures for a limited period. Fuel cell systems would benefit from an ESS to handle transients and quick ramp-ups. A "ship" ESS supports single generator operation, with fault ride through and black start capability (Bellamy and Bray, 2015).

\section{Modelling ESS for ATK-R}

Two parametric models were developed to characterise a dedicated EMRG ESS for the continuous and burst firing modes. In the continuous mode, the ESS is recharged between shots (Figure 11a). In burst mode (Figure $11 b)$ the ESS is charged in the interval between bursts, once the ESS is charged, the ESS is decoupled from the power system and discharges into the PFN in succession to achieve the rates of fire required by the scenario.

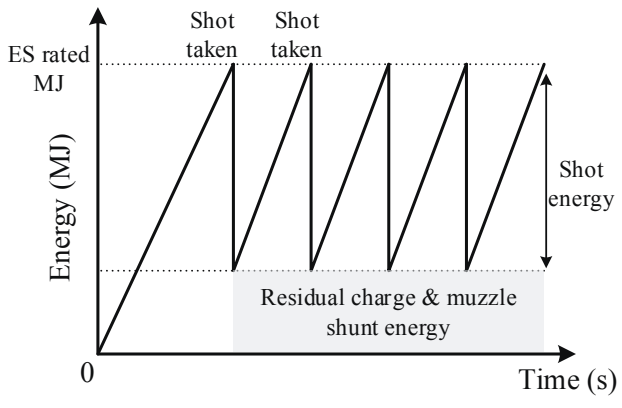

a)

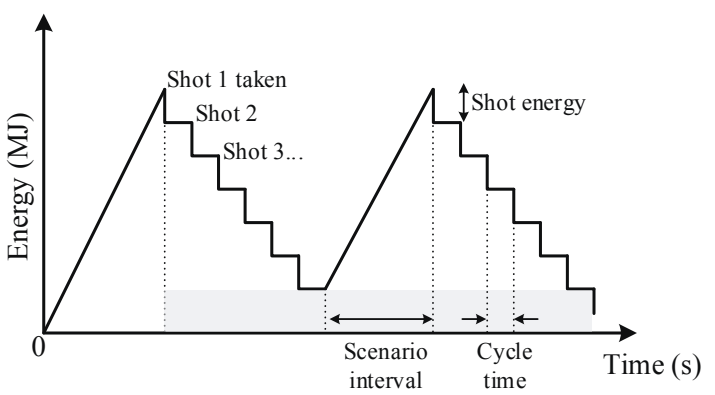

b)

Figure 11: EMRG shot profile for a) continuous and b) burst mode

Figure 12 describes the supercapacitor characterisation model. The supercapacitor module data used was from Skeleton Technologies (2016), the modules rated at $170 \mathrm{~V}$ with a capacitance of $53 \mathrm{~F}$. It is noted that key technical challenges of supercapacitor string integration is their voltage limit, currently $2 \mathrm{kV}$ (Southall et al. 2017), varying equivalent capacitance and voltage between modules in the strings, the latter factors can affect the charging and discharging characteristics of the ESS. Capacitor banks can attain higher voltages (Whitelegg, 2016), but only with significant increases in volume and weight. The maximum supercapacitor string voltage was therefore set at $11 \mathrm{kV}$, minimising the charging current drawn from the supply. It was assumed that $10 \%$ of the shot energy could be recovered via a muzzle shunt (Bernardes et al. 2002) and a 20\% energy margin was applied to maintain a residual charge following an EMRG shot. The ESS mass and volume characteristics are exclusive of string enclosures, cooling, control and conversion equipment. 


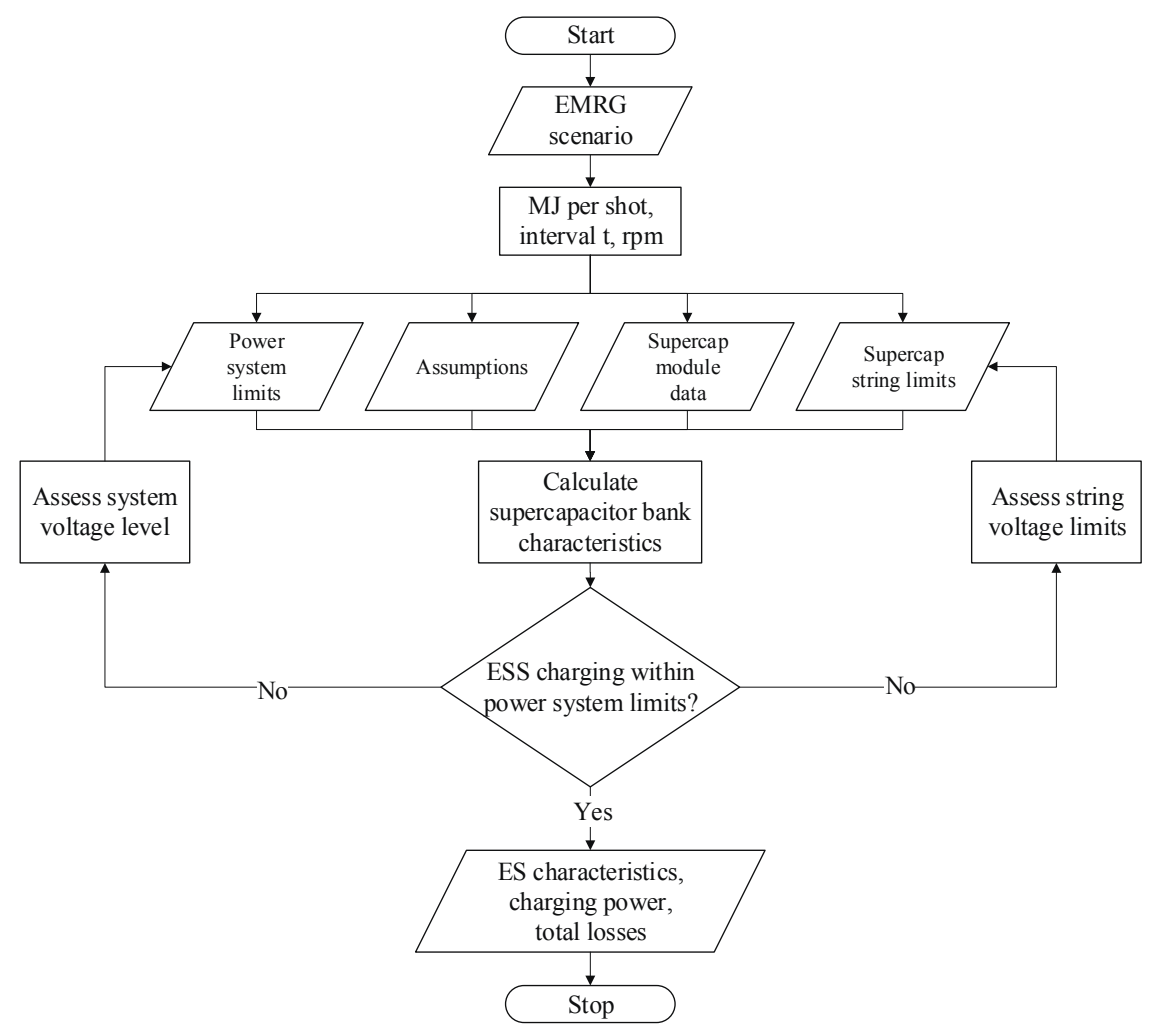

Figure 12: EMRG ESS characterisation procedure

The parametric battery-sizing model is less complex than the EMRG ESS, the inputs are power for a required time and battery module data. The battery constraints are string voltage limit of $1000 \mathrm{~V}$ and maximum $4000 \mathrm{~A}$ discharge current per battery bank. The model allows the user to assess two options based on modules comprising Lithium-ion NMC cells, 'energy' and 'power'. The module data used in the model is from Plan B Energy Storage (2017) summarised in Table 7, the maximum current limit defines the number of strings possible per bank. To preserve battery life a depth of discharge limit of $80 \%$ was assumed. The model outputs the volume, mass, rated energy and power of the battery system, exclusive of conversion equipment.

Table 7: Battery option characteristics

\begin{tabular}{l|l|l}
\hline \multirow{2}{*}{ Parameter } & \multicolumn{2}{|c}{ Battery option } \\
\cline { 2 - 3 } & Power & Energy \\
\hline String nominal voltage & \multicolumn{2}{|c}{$888 \mathrm{~V}$} \\
\hline String nominal discharge current & $225 \mathrm{~A}$ & $160 \mathrm{~A}$ \\
\hline String peak discharge current & $450 \mathrm{~A}$ & $336 \mathrm{~A}$ \\
\hline String volumetric power density & $276 \mathrm{~kW} / \mathrm{m}^{3}$ & $206 \mathrm{~kW} / \mathrm{m}^{3}$ \\
\hline String gravimetric power density & $420 \mathrm{~kW} / \mathrm{te}$ & $314 \mathrm{~kW} / \mathrm{te}$ \\
\hline String volumetric energy density & $45 \mathrm{kWh} / \mathrm{m}^{3}$ & $69 \mathrm{kWh} / \mathrm{m}^{3}$ \\
\hline String gravimetric energy density & $68 \mathrm{kWh} / \mathrm{te}$ & $105 \mathrm{kWh} / \mathrm{te}$ \\
\hline Maximum parallel strings per bank & 9 & 13
\end{tabular}

To size the battery ESS for each option in ZEOLIT, a minimum permissible speed whilst firing was defined as 21 knots. Available DG, SOFC or GT power above this was compared to the required EMRG ESS input power. If the existing power and propulsion system did not offer sufficient power, a battery ESS was sized to provide the rest. The battery ESS was sized to support three engagements before requiring recharge.

\section{Discussion of results}

Graphs of the resulting design options for the various topologies and EMRG options are included in Appendix 1. The initial ZEOLIT runs indicate that a heavy EMRG could be carried by a corvette in the 2000-3500 tonne 
displacement range (Figure A1 and A2) and that reducing maximum speed from 35 to 25 knots permits the minimum size to be reduced to 2000 tonnes. Even with its' significantly greater volume demand, adopting methanol fuel in a SOFC powered ship did not result in excessively large vessels, with displacements remaining in the 2000-2600 tonne range, with 2300 tonnes being the value with the most permissible options (Figure A11).

The use of a battery based "ship" ESS to charge the supercapacitor "weapon" ESS is found to be vital for smaller or slower vessels. For 35 knot ships, above approximately 2500 tonnes, the boost GT have sufficient combined power to charge the weapon ESS directly (Figure A1 and A3). For many ship options, however, only 40 tonnes of battery ESS may be required (Figure A4). For slower, low power ships, the Battery ESS is far larger, up to 190 tonnes (9\% of displacement) on the smallest vessels (Figure A9). However the larger ESS stores sufficient energy - up to $12 \mathrm{MWhrs}$ - to permit potentially useful operational times on battery power only (Figure A10). For designs with multiple smaller EMRG, the battery ESS will be much smaller if only a single EMRG is to be operated at any one time, as boost GT may be sufficient (Figure A14 and A15).

The inclusion of arrangements in ZEOLIT show that the size of the GT space amidships is a particular issue, and most options have insufficient volume in this area (Figure A5) whilst lower speed options have less issues with space (Figure A13), even though methanol tankage can be almost 20\% of displacement (Figure A12).

\section{Conclusions and future work}

The Advanced Technology Corvette - Railgun (ATK-R) links several areas of ongoing research at UCL. This paper has discussed two of these; the ZEOLIT concept design tool; and PhD research into Energy Storage Systems (ESS) in warship power and propulsion systems. The initial design studies have shown that large railguns can be compatible with small warships. High speed design options with boost GT have the potential to use a shoot-orsprint concept, where the GT powers the EMRG via a dedicated high speed generator. Lower speed options will require significant battery ESS.

This is an ongoing project and future work is planned including the assessment of more ship impacts from design decisions such as AC or DC; refinement of the SOFC concept to include GT options; and integration with wargaming and effectiveness modelling.

\section{Acknowledgements}

Development of ZEOLIT was carried out as part of the Preliminary Ship Design General Arrangements NICOP project and its successor NICOP, both funded by Ms. Kelly Cooper from the US Navy Office of Naval Re-search, and this support is gratefully acknowledged. The conclusions presented are the opinions of the authors and do not represent MoD or DoD policy.

\section{References}

Andrews D.J.: "A Comprehensive Methodology for the Design of Ships (and Other Complex Systems)", Proceedings of the Royal Society, Series A (1998) 454, p.187-211, Jan 1998.

Andrews D.J. Bucknall R. \& Pawling R.J.: "The Impact of Integrated Electric Weapons on Future Warship

Design", INEC 2010, IMarEST, Portsmouth, UK.

Andrews D.J. Bucknall R. Pawling R.J. Greig A. \& McDonald T.: "The Impact of Integrated Electric Weapons on Future Warship Design Using Conventional and Unconventional Hullforms", Engine as a Weapon (EAAW) 2011, IMarEST, London.

Bellamy G. \& Bray R.,: "Matching energy storage to Naval platform requirements - benefits and challenges of integration”, In: Engine as a Weapon VI., Bath: IMarEST, 2015.

Bernardes J.S. Lacava G.P. \& Schrader M.J.: "Analysis of a railgun capacitor-muzzle-shunt energy recovery scheme”, In: Conference Record of the Twenty-Fifth International Power Modulator Symposium, 2002 and 2002 High-Voltage Workshop, IEEE, 347-350.

Calfo R.M. et al.: "High-speed generators for power-dense, medium-power, gas turbine generator sets", Naval Engineers Journal, 120 (4), 45-54, 2008.

Chowaniec Z. Forbes J. \& Shaw J.: "High speed motor propulsion for warships", In: International Naval Engineering Conference, 2012, IMarEST. 
Daniels A.S. Tahmasbi F. \& Singer D.J.: "Intelligent ship arrangement (ISA) methodology improvements and capability enhancements", IMDC 2009, Trondheim, Norway, May 2009.

Doerry N. Amy J. \& Krolick C.: "History and the Status of Electric Ship Propulsion, Integrated Power Systems, and Future Trends in the U.S. Navy", Proceedings of the IEEE, 103 (12), 2243-2251, 2012.

DNV-GL: "Study on the use of Fuel Cells in Shipping", 2017.

Gattozzi, A.L., Strank, S.M., Pish, S.P., Herbst, J.D., Hebner, R.E., and Engelkemeir, F.D., 2017. Power converter design options for the 12 kVdc bus system. 2017 IEEE Electric Ship Technologies Symposium, ESTS 2017, 246-250.

General Atomics: "Missile Defense Systems - Electromagnetic Gun Systems", http://www.ga.com/missiledefense-systems, 2018.

Kirtley J.L. Banerjee A. \& Englebretson S.: "Motors for Ship Propulsion”, Proceedings of the IEEE, 103 (12), 2320-2332, 2015

Kyocera: “KYOCERA Develops Industry's First 3-Kilowatt Solid-Oxide Fuel Cell for Institutional Cogeneration", July 6, 2017, https://global.kyocera.com/news/2017/0702_bnfo.html

McDonald T. Andrews, D.J. \& Pawling R.J.: “A Demonstration of an Advanced Library Based Approach to the Initial Design Exploration of Different Hullform Configurations", Computer-Aided Design, Vol. 44, Issue 3, March 2012, pp. 209-223.

Meggs R.W. \& Pollard C.: "Protective Devices for DC Power Networks", in International Naval Engineering Conference, 2016, Bristol: IMarEST, pp. 1-12.

Office of Naval Research (ONR): "Naval EM Railgun Innovative Naval Prototype”, Precision Strike Armaments Precision Strike Armaments Technology Fire Power Forum Technology Fire Power Forum, June 2008.

Pawling R.J. Piperakis A.S. \& Andrews D.J.: "Developing Architecturally Oriented Concept Ship Design Tools for Research and Education”, International Marine Design Conference (IMDC) 2015, Tokyo, May 2015.

Plan B Energy Storage: PBES Specification Sheet, 2017.Singer D.J. Doerry N. \& Buckley M.E.: "What is SetBased Design?”, Naval Engineers Journal, Vol 121/4, October 2009.

Rodrigues R. Jiang T. Du Y. Cairoli P. \& Zheng H.: "Solid state circuit breakers for shipboard distribution systems", 2017 IEEE Electric Ship Technologies Symposium, ESTS 2017, 406-413.

Simmonds O.J.: “Advanced hybrid systems and new integration challenges”, in International Naval Engineering Conference,2016, Bristol: IMarEST, pp. 1-10.

Skeleton Technologies: “Technical specification: Module SMOD170V53F”, 2016.

Southall M. et al.: "Application \& Optimisation of Electromagnetic Catapult Launch Systems, and Benefits of Integrated Energy Storage", in Engine as a Weapon VII, 2017, Bristol: IMarEST, pp. 1-8.

Tate A. \& Rumney T." "Taking the Dragon (Fire ) to sea: UK MOD efforts to de-risk the integration of Laser DEW", in Engine as A Weapon VII., 2017 Bristol: IMarEST, pp. 1-9.

Van Oers B.J.: “A Packing Approach for the Early Stage Design of Service Vessels", PhD Thesis, Delft University of Technology, Delft, The Netherlands, 2011.

Vu,T.V. Gonsoulin D. Perkins D. Diaz F. Vahedi H. \& Edrington C.S.: "Predictive energy management for MVDC all-electric ships", 2017 IEEE Electric Ship Technologies Symposium, ESTS 2017, 327-331.

Whitelegg I.: "Power system design considerations when integrating electromagnetic railguns with electric warships", In: INEC 2016, Bristol: IMarEST. 
Whitelegg I.: "On the integration of electromagnetic railguns with warship electric power systems", PhD Thesis, UCL, 2016.

Whyatt G.A. \& Chick L.A.: "Electrical Generation for More-Electric Aircraft using Solid Oxide Fuel Cells", PNNL-21382, US DoE, April 2012.

\section{Appendix 1: Graphs of Results}

\subsection{Topology $1 a / 1 b$}

Single heavy EMRG, 35 knot sprint speed, battery ESS included where needed.

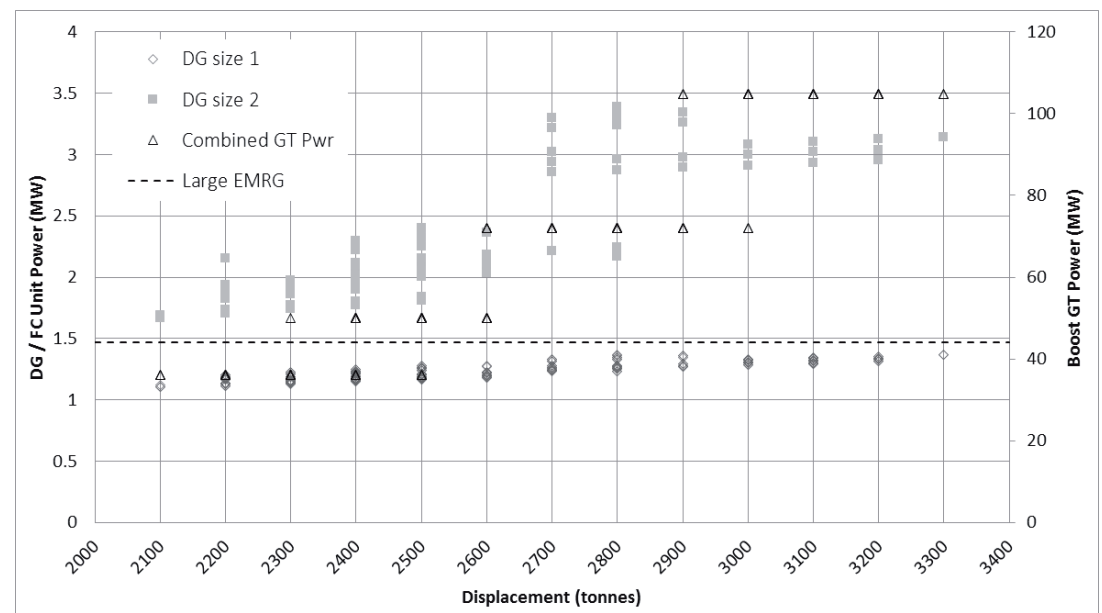

Figure A1: Variation in machinery unit power ratings with displacement for topology $1 \mathrm{a} / 1 \mathrm{~b}$

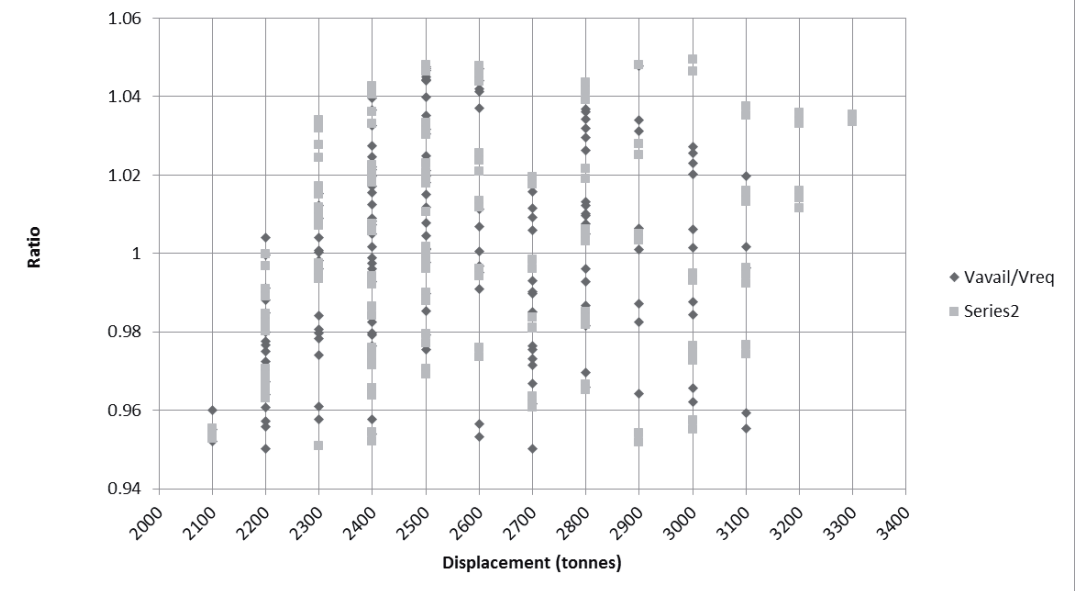

Figure A2: Range of acceptable designs for topology 1a/1b
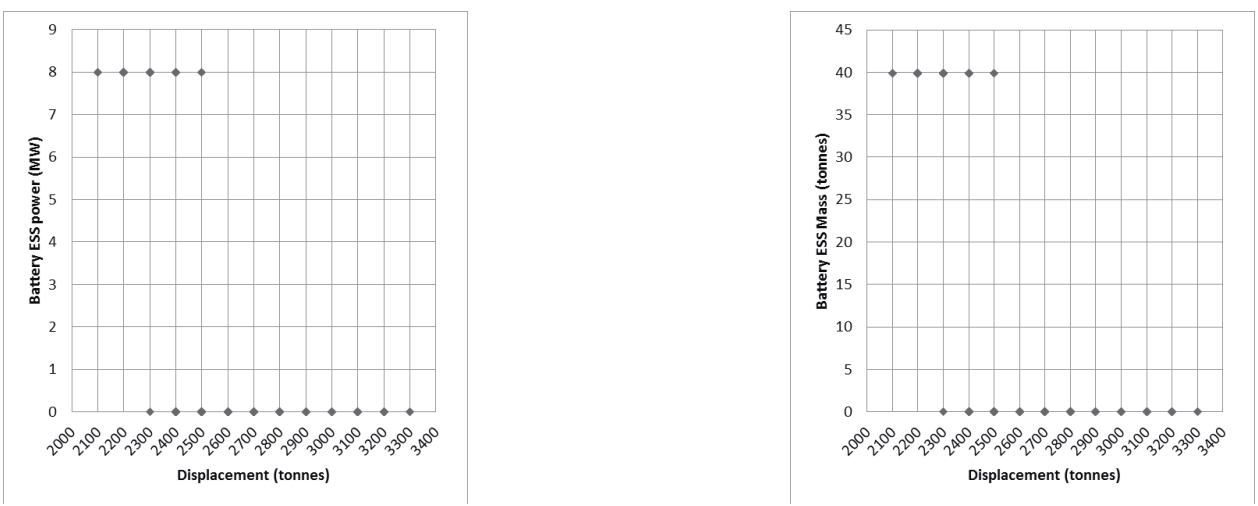
Figure A3: Variation in ESS power with Figure A4: Variation in ESS mass with displacement displacement

\begin{tabular}{|c|c|c|c|c|c|c|c|c|c|}
\hline & $\mathrm{H}$ & G & $\mathrm{F}$ & $E$ & D & C & B & A & \\
\hline \multirow[t]{4}{*}{ Much too small } & 0 & 0 & 0 & 0 & 0 & 0 & 0 & 0 & 2 \\
\hline & 0 & 0 & 0 & 38 & 0 & 0 & 0 & 0 & 1 \\
\hline & 16 & 0 & 0 & 0 & 0 & 0 & 24 & 100 & -2 \\
\hline & 64 & 19 & 0 & 94 & 0 & 0 & 0 & 71 & -3 \\
\hline
\end{tabular}

Figure A5: Percentage of options with less than $80 \%$ of required volume in each layout zone, GT machinery space is in layout zone E -3

\subsection{Topology $2 a$}

Single heavy EMRG, 25 knot sprint speed, battery ESS included where needed.

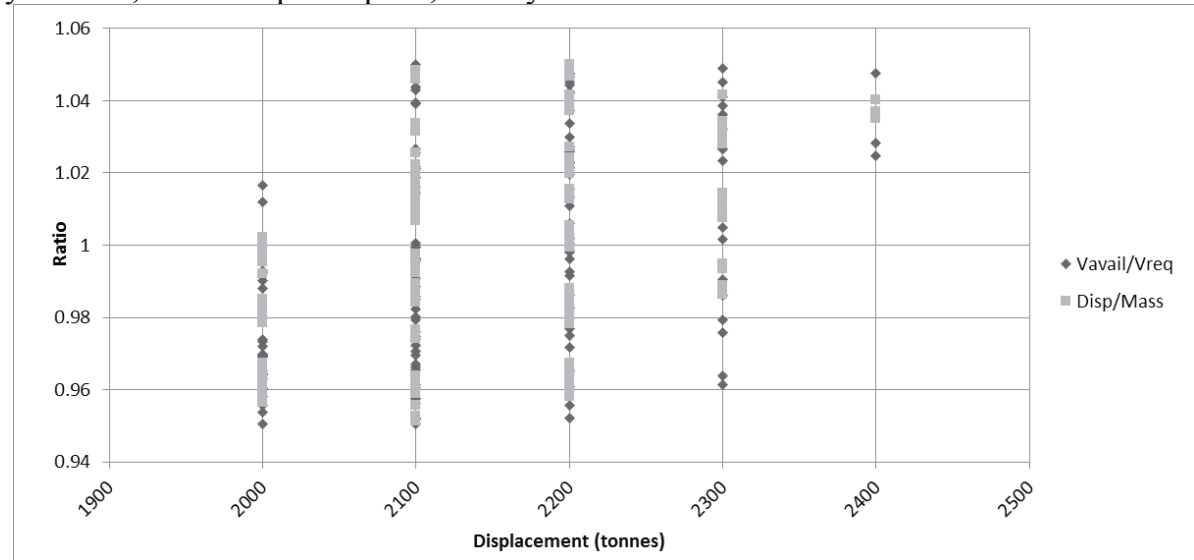

Figure A6: Range of displacements generated for topology 2a

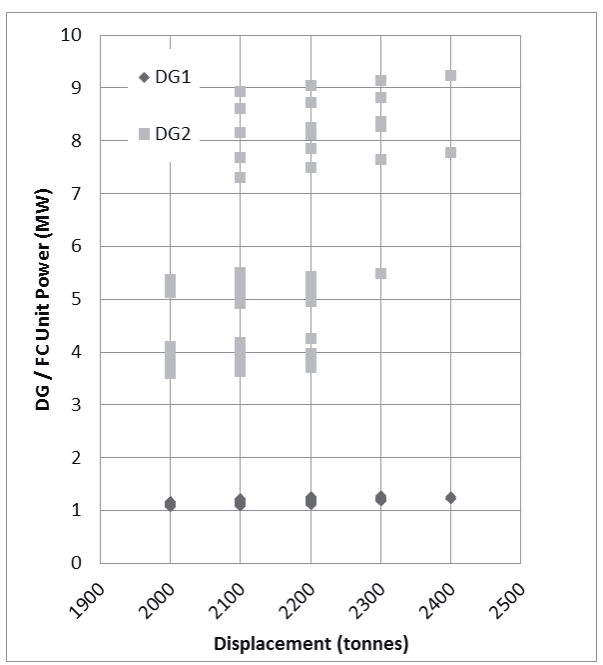

Figure A7: Variation in unit DG power

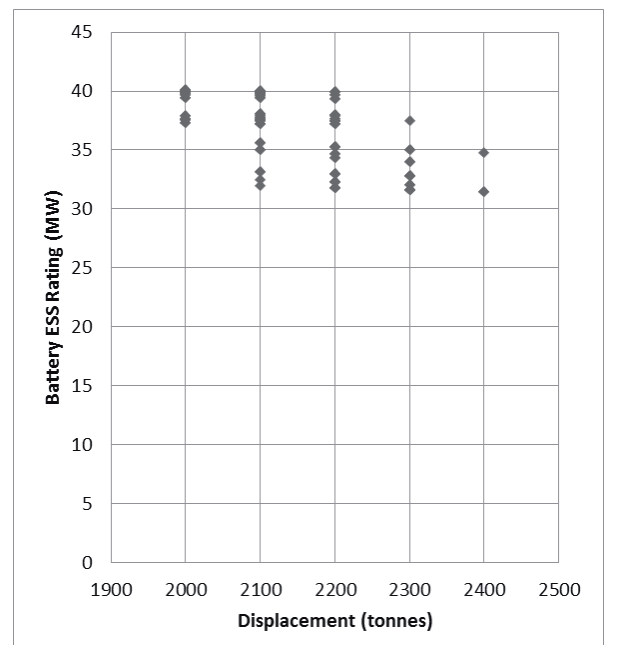

Figure A8: Variation in battery ESS power 


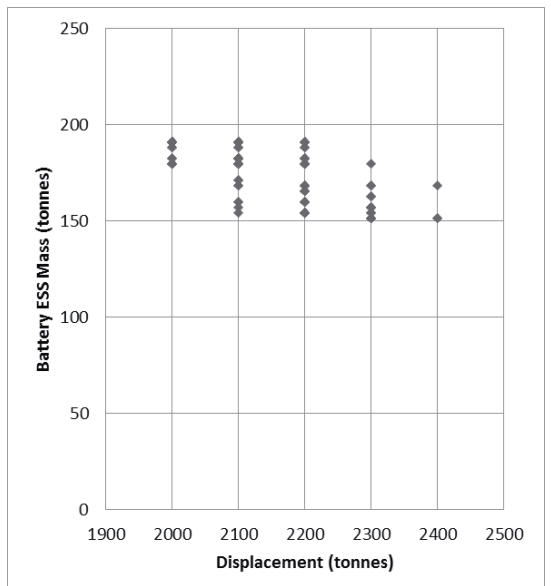

Figure A9: Variation in battery ESS mass

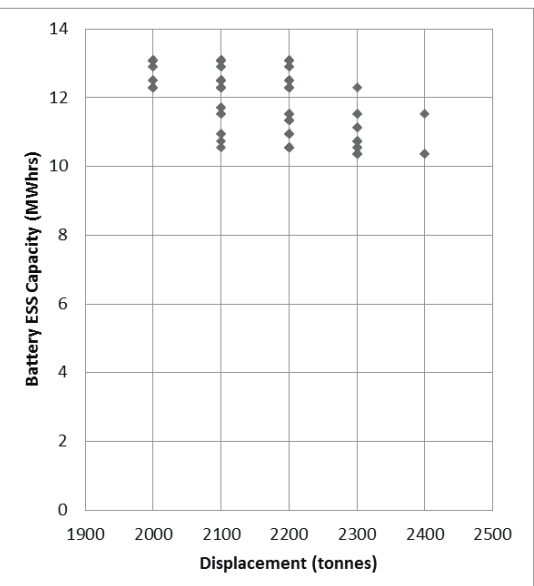

Figure A10: Variation in battery ESS energy

\subsection{Topology $2 b$}

Single heavy EMRG, 25 knot sprint speed, SOFC with methanol fuelling, battery ESS included where needed.

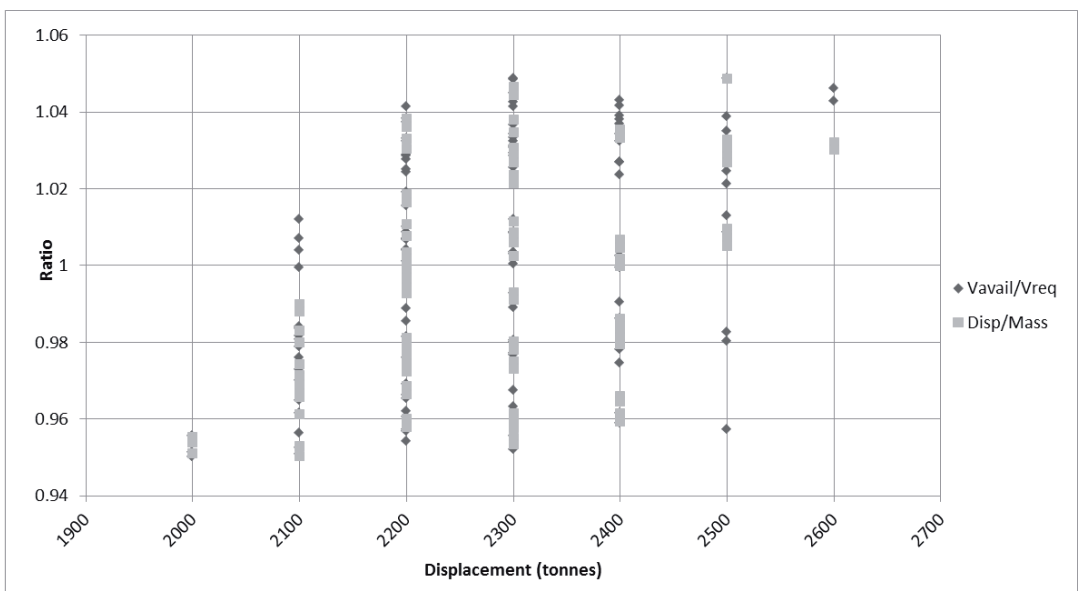

Figure A11: Range of displacements for Topology $2 b$

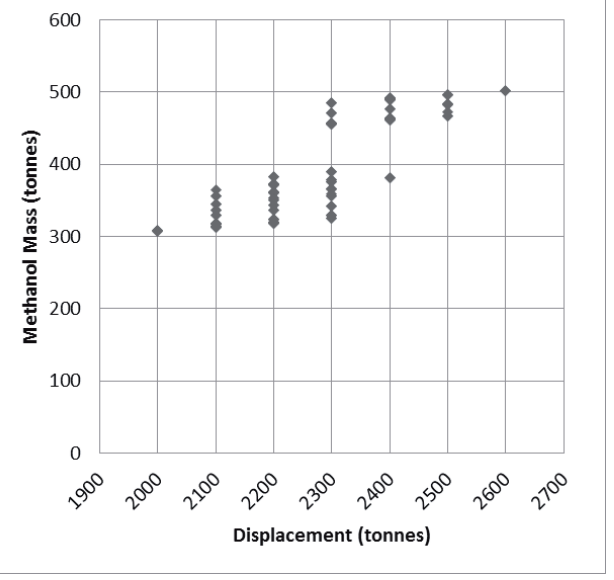

Figure A12: Methanol fuel requirements

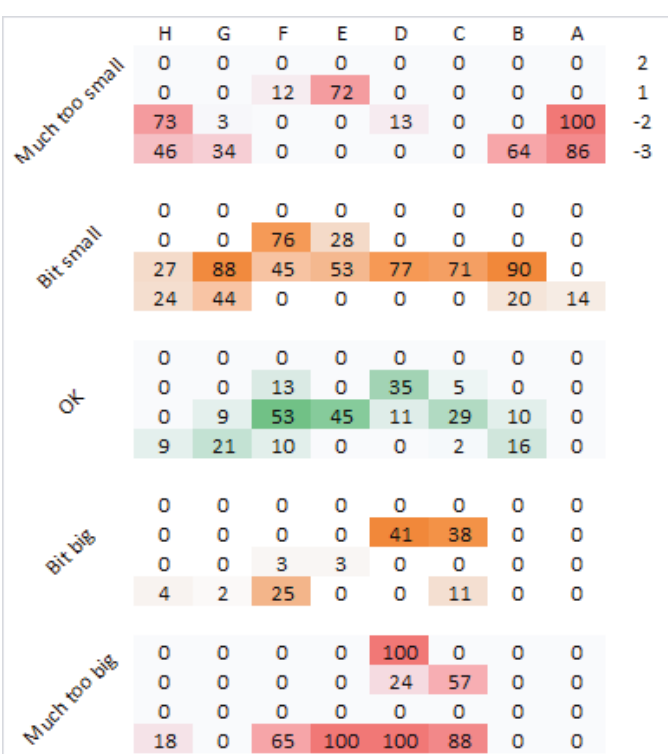

Figure A13: Aggregated volume results for all options green is OK, red is too small or too large 


\subsection{Topology 1a/b, Multiple EMRG}

One medium and one light EMRG, 35 knot sprint speed, battery ESS included where needed.

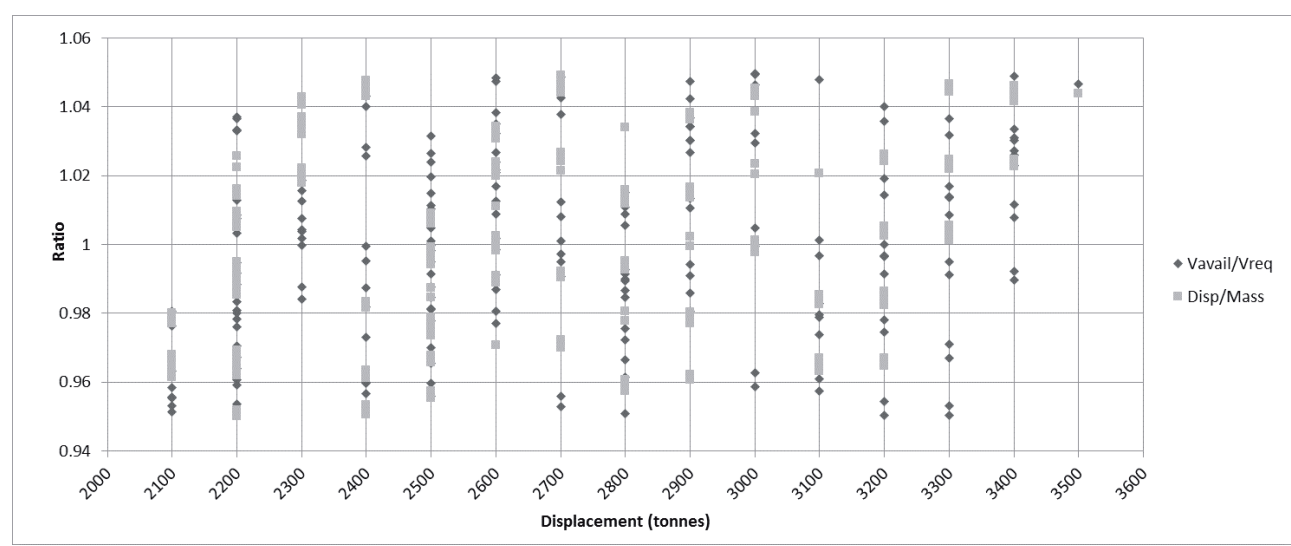

Figure A14: Range of options generated for a two-EMRG design

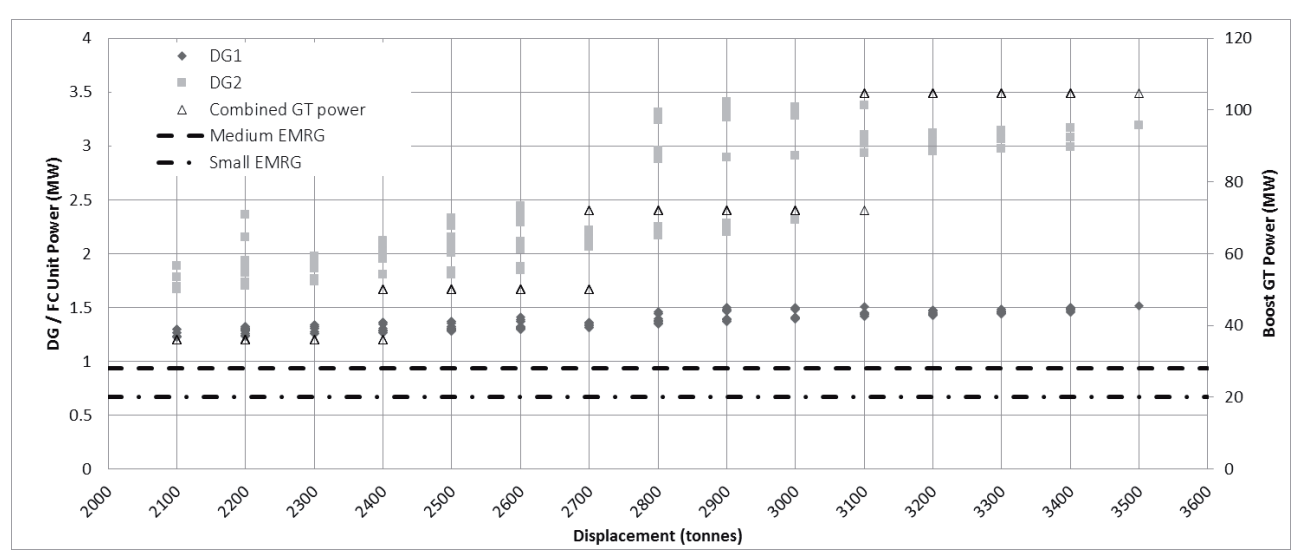

Figure A15: Variation in prime mover power with displacement 